\title{
Active Avoidance Requires a Serial Basal Amygdala to Nucleus Accumbens Shell Circuit
}

\author{
Franchesca Ramirez, ${ }^{1,2 \star}$ Justin M. Moscarello, ${ }^{1 \star}$ Joseph E. LeDoux, ${ }^{1,2,3}$ and Robert M. Sears ${ }^{1}$ \\ ${ }^{1}$ Center for Neural Science, ${ }^{2}$ Department of Psychology, New York University, New York, New York 10003, and ${ }^{3}$ Emotional Brain Institute, Nathan Kline \\ Institute for Psychiatric Research, Orangeburg, New York 10962
}

Freezing is a species-typical defensive reaction to conditioned threats. While the neural circuitry of aversive Pavlovian behavior has been extensively studied, less is known about the circuitry underlying more active responses to danger. Here we show that the flow of information between the basal amygdala (BA) and the nucleus accumbens (NAcc) is necessary for signaled active avoidance behavior. Rats trained to avoid shock by shuttling during an auditory conditioned stimulus showed increased expression of the activity-dependent protein c-Fos in the NAcc, specifically the shell subregion (NAccSh). Silencing neural activity in the NAccSh, but not in the adjacent NAcc core, disrupted avoidance behavior. Disconnection of the BA and the NAccSh was just as effective at disrupting avoidance behavior as bilateral NAccSh inactivations, suggesting learned avoidance behavior requires an intact BA-NAccSh circuit. Together, these data highlight an essential role for the amygdalar projection to the ventral striatum in aversively motivated actions.

Key words: two-way signaled active avoidance; aversive; fear conditioning; motivation; negative reinforcement

\section{Introduction}

Pavlovian defensive reactions depend on a well characterized amygdalar substrate. The lateral nucleus of the amygdala (LA) receives sensory information about conditioned stimuli (CSs) from its cortical and thalamic inputs. This information is processed through the basal amygdala (BA) and engages central amygdala (CeA) projections to brainstem effector sites. CeA target regions, such as periaqueductal gray, drive freezing and other innate defensive reactions to learned threats (LeDoux et al., 1988; Fanselow, 1994; Maren, 2001; McNally et al., 2011).

Aversive CSs can also evoke a contrasting class of defensive behaviors, such as escape and avoidance responses, that allow the subject to influence or control the impact of environmental threats (McAllister et al., 1971; Levis, 1989; Cardinal et al., 2002). Though these CS-evoked actions also rely on both LA and BA, they do not require CeA (Amorapanth et al., 1999; Choi et al., 2010), indicating that the relevant amygdalar efferents differ as well. The BA projection to the nucleus accumbens (NAcc; Kelley et al., 1982; Groenewegen et al., 1999) has been hypothesized as the key output pathway mediating aversively motivated action (Cain and LeDoux, 2008; Elliot, 2008), though its involvement has never been empirically demonstrated.

\footnotetext{
Received April 2, 2014; revised Jan. 4, 2015; accepted Jan. 19, 2015.

Author contributions: F.R., J.M.M., and R.M.S. designed research; F.R. and R.M.S. performed research; F.R., J.M.M., and R.M.S. analyzed data; F.R., J.M.M., J.E.L., and R.M.S. wrote the paper.

This work was supported by a National Institute of Mental Health grant to J.E.L. (R01 MH38774), a National Science Foundation grant to J.E.L. (0920153), and a National Institute on Drug Abuse grant to J.E.L. (R01 DA029053). The authors thank C.R. Farb and M. Hou for technical assistance and C.K. Cain for help with the manuscript.

The authors declare no competing financial interests.

*F.R. and J.M.M. contributed equally to this work.

Correspondence should be addressed to Robert M. Sears, 4 Washington Place, New York, NY 10003. E-mail: robert.sears@nyu.edu.

DOI:10.1523/JNEUROSCI.1331-14.2015

Copyright $\odot 2015$ the authors $\quad 0270-6474 / 15 / 353470-08 \$ 15.00 / 0$
}

The NAcc is an important interface between motivational processing and motor control (Mogenson et al., 1980). Evidence from the appetitive literature implicates the BA-NAcc projection in the Pavlovian modulation of instrumental action (Di Ciano and Everitt, 2004; Haselgrove et al., 2010; Shiflett et al., 2010; Stuber et al., 2012; Corbit and Balleine, 2005; Ambroggi et al., 2008; Corbit et al., 2001). Though often considered in the context of reward and positive reinforcement, NAcc neurons also process aversive information, responding to both noxious stimuli and the cues that predict them (Schoenbaum and Setlow, 2003; Roitman et al., 2005). These data support the hypothesis that NAcc is the target of BA outputs that mediate defensive actions (Cain and LeDoux, 2008; Delgado et al., 2008; Lázaro-Muñoz et al., 2010).

The experiments reported here tested the role of the BA-NAcc projection in a signaled active avoidance paradigm for rats. As in aversive Pavlovian conditioning, animals learn that a conditioned stimulus (i.e., a tone) predicts an unconditioned stimulus (US; i.e., foot shock). As training proceeds, animals learn to avoid the US by shuttling across a divided chamber during the CS, which terminates the tone and prevents the impending shock. We demonstrate that signaled active avoidance requires the flow of information between BA and the shell region of NAcc (NAccSh), and that this substrate is dissociable from the pathways of Pavlovian reactions, such as freezing.

\section{Materials and Methods}

Subjects. Subjects were male Sprague Dawley rats ( $n=84$; Hilltop Laboratories) weighing $\sim 250-300 \mathrm{~g}$ at the time of arrival. Rats were housed individually on a $12 \mathrm{~h} \mathrm{light/dark} \mathrm{cycle} \mathrm{(7} \mathrm{A.M.-7} \mathrm{P.M.)} \mathrm{and} \mathrm{had} \mathrm{access} \mathrm{to}$ food and water ad libitum. The New York University Animal Care and Use Committee approved all procedures.

Two-way signaled active avoidance apparatus. Rats underwent signaled active avoidance (SigAA) training in six identical Plexiglas and aluminum shuttle boxes $[25$ (depth) $\times 50$ (width) $\times 30$ (height) $\mathrm{cm}$ ]. Each was 
separated into two identical chambers by metal dividers with a small passage that allowed rats to move freely from side to side. The grid floor had 32 stainless steel bars arranged in parallel to the dividers (H10-11RXX-SF, Coulbourn Instruments). Subjects were presented with a $5 \mathrm{kHz}$, $70 \mathrm{~dB}$ tone CS that signaled a $0.7 \mathrm{~mA}$ foot-shock US, which was delivered by a scrambled shocker (H13-15, Coulbourn Instruments). The interior of the shuttle box was dimly illuminated with two small $0.5 \mathrm{~W}$ light bulbs. Each shuttle box was inside a larger sound-attenuated cubicle (H10-24A, Coulbourn Instruments). Shuttling, or movement from one chamber to the other, was measured by two infrared arrays made up of five emitterdetector sets on either side of the metal division between chambers. A computer, installed with Graphic State 2 software and connected to the chambers via the Habitest Linc System (Coulbourn Instruments), controlled the presentation of stimuli during behavioral sessions.

Aversive Pavlovian conditioning apparatus. Rats underwent conditioning in identical conditioning chambers (Rat Test Cage, Coulbourn Instruments) constructed of aluminum and Plexiglas walls, with metal stainless steel rod flooring that was attached to a shock generator (H1315, Coulbourn Instruments). The chambers were lit with a single house light, and each chamber was enclosed within a sound-isolation cubicle (H10-24A, Coulbourn Instruments). Long-term memory (LTM) testing took place within a modified version of the context, with smooth black plastic flooring, mild peppermint scent, and a striped pattern on the Plexiglas door. An infrared digital camera, mounted on top of each chamber, enabled videotaping during behavioral procedures for subsequent behavioral scoring. A computer, installed with Graphic State 2 software and connected to the chambers via the Habitest Linc System (Coulbourn Instruments), controlled the presentation of stimuli during behavioral sessions.

Cannulae implantation procedure. Procedures were similar to those previously described (Sears et al., 2013). Animals were anesthetized with a mixture of ketamine $(75 \mathrm{mg} / \mathrm{kg})$ and xylazine $(10 \mathrm{mg} / \mathrm{kg})$ and mounted in a stereotaxic frame (David Kopf Instruments). The skull was exposed and bilateral boreholes were made. Animals were implanted with 26 gauge cannulae targeting the NAccSh, the NAcc core (NAccCo), and/or the BA. Target coordinates were as follows: NAccSh, $+1.5 \mathrm{~mm}$ anteroposterior (AP), $\pm 1.5 \mathrm{~mm}$ mediolateral $(\mathrm{ML}),-5.9 \mathrm{~mm}$ dorsoventral (DV); NAccCo, $+1.5 \mathrm{~mm} \mathrm{AP,} \pm 1.8 \mathrm{~mm} \mathrm{ML},-4.7 \mathrm{~mm} \mathrm{DV}$; BA, -3.3 $\mathrm{mm} \mathrm{AP}, \pm 5.2 \mathrm{~mm} \mathrm{ML},-7.0 \mathrm{~mm}$ DV. Cannulae were secured using stainless steel screws and dental acrylic. Rats were allowed 2 weeks recovery time before behavioral training.

Muscimol injections. Muscimol was prepared in artificial CSF, pH 7.4, for brain microinfusions of $100 \mathrm{ng} / 0.3 \mu \mathrm{l}$. Infusions were accomplished using $10 \mu \mathrm{l}$ Hamilton syringes (Hamilton) attached to $0.015 \times 0.043 \times$ 0.014 inch polyethylene tubing (A-M Systems). Drug was delivered through internal cannulae at a constant rate of $0.1 \mu \mathrm{l} / \mathrm{min}$ using an infusion pump (PHD 2000, Harvard Apparatus). Following infusion, cannulae were left in place for $1 \mathrm{~min}$ to allow for drug diffusion. All muscimol injections began $\sim 20$ min before behavior testing.

Two-way SigAA paradigm. Procedures were similar to those of previous studies by our group (Choi et al., 2010; Moscarello and LeDoux, 2013). Rats were placed in the shuttle box and given a 5 min acclimation period. On the first day of training, rats received a single unavoidable Pavlovian trial consisting of a $15 \mathrm{~s}$ CS followed immediately by a $1 \mathrm{~s}$ US $(0.7 \mathrm{~mA})$. This was followed by 30 avoidance trials with an average intertrial interval of $2 \mathrm{~min}$. Each trial consisted of a tone CS that lasted $\leq 15 \mathrm{~s}$. Shuttling during the CS terminated the tone and prevented delivery of the US (avoidance response). If no shuttling occurred during the $15 \mathrm{~s} \mathrm{CS}$, the foot-shock US was presented until the rat shuttled (escape response) or for $\leq 15$ s. All sessions subsequent to the first involved 30 avoidance trials without the initial Pavlovian trial. All avoidance studies involved $3 \mathrm{~d}$ of training with a test on the fourth day. Animals were removed from a given study if avoidance responses were at $\leq 20 \%$ for the $3 \mathrm{~d}$ of SigAA training (Choi et al., 2010).

The c-Fos study involved four groups, including a master, yoke, box control, and handling control. The master group was trained to avoid the US by shuttling during the CS, as described above. In contrast, each yoke was linked to a master and received the same pattern of stimuli, but was not allowed the behavioral control necessary to acquire the avoidance contingency. The box control group was placed in the chamber for same period of time as the masters and yokes, but received no conditioning. The handling control group was habituated to experimenters, but received no conditioning at any point and thus served as a baseline to which c-Fos quantification could be normalized.

Masters and yokes received three sessions of SigAA training. The fourth session involved 10 unreinforced, unyoked avoidance CSs presented to both groups. This US-free test allowed us to isolate the effects of the avoidance contingency on behavior and neuronal activity. Ninety minutes after the end of this session, animals were deeply anesthetized, perfused with $4 \%$ paraformaldehyde, and had their brains removed for immunohistochemistry as described below.

For pharmacological studies (i.e., NAccSh, NAccCo, and BA-NAccSh inactivation experiments), animals received $3 \mathrm{~d}$ SigAA training and were then given infusions of muscimol or vehicle $20 \mathrm{~min}$ before the fourth session of SigAA. Animals were then given an additional fifth session to re-establish baseline levels of avoidance behavior. For the NAccSh inactivation experiment, the fourth session was recorded on DVD by overhead camera, and CS-evoked freezing was scored off-line. These data were not available for NAccCo and BA-NAccSh studies.

Aversive Pavlovian conditioning. To test the role of NAccSh in the expression of a purely Pavlovian form of memory, we conducted a series of procedures similar to those of previous studies (Sears et al., 2013). Briefly, animals underwent a habituation session during which they were exposed to the conditioning chamber for $30 \mathrm{~min}$. Twenty-four hours later, animals were threat conditioned. Following a 5 min acclimation period, animals received three CS-US pairings in which the CS was a $15 \mathrm{~s}$ presentation of a $5 \mathrm{kHz}, 80 \mathrm{~dB}$ tone and the US was a standard, $1 \mathrm{~s}$ coterminating foot shock $(0.7 \mathrm{~mA})$. Following training, animals were returned to the vivarium. Chamber floors, trays, and walls were cleaned with $70 \%$ ethanol and dried between sessions. Twenty-four hours following training, animals were infused with muscimol as already described and tested in a separate context (see Apparatus) for expression of LTM, through the presentation of five CSs (Schafe and LeDoux, 2000). Behavior sessions were recorded and freezing time was quantified off-line. Freezing behavior was scored by a trained rater blinded to treatment conditions. Data were represented as the mean percentage of time freezing during all CS presentations. After these experiments, animals were perfused with $10 \%$ formalin and cannulae targeting was histologically verified as described below.

Pavlovian test following SigAA training. To isolate the effects of NAccSh inactivation on Pavlovian reactions (freezing) following avoidance learning, animals underwent three sessions of the two-way SigAA paradigm described above. Twenty-four hours later, animals received muscimol or vehicle infusions into NAccSh before being exposed to $5 \mathrm{CSs}(15 \mathrm{~s}, 5 \mathrm{kHz}$, $70 \mathrm{~dB}$ ) in a standard cubical conditioning chamber, identical to that used for the LTM test in the aversive Pavlovian conditioning experiment. Freezing behavior was recorded by overhead cameras and scored off-line.

Histology and immunohistochemistry. For cannula placement, rats were anesthetized with chloral hydrate $(150 \mathrm{mg} / \mathrm{kg})$ and transcardially perfused $10 \%$ formalin in $0.1 \mathrm{M}$ phosphate buffer ( $\mathrm{PB}), \mathrm{pH}$ 7.4. Tissue was processed as previously described (Sears et al., 2013). The brains were sectioned into $50 \mu \mathrm{m}$ sections using a microtome. Sections were stained with cresyl violet, mounted, and examined under a light microscope.

Immunohistochemistry procedures were performed as previously described (Moscarello and LeDoux, 2013), with a few changes. Ninety minutes after SigAA rats were anesthetized with chloral hydrate $(150 \mathrm{mg} / \mathrm{kg})$ and perfused transcardially with $4 \%$ paraformaldehyde in $0.1 \mathrm{M} \mathrm{PB}, \mathrm{pH}$ 7.4, brains were removed and postfixed in $4 \%$ paraformaldehyde for $24 \mathrm{~h}$. Coronal sections $(30 \mu \mathrm{m})$ were then cut using a vibrating blade microtome (Leica Biosystems). Every fifth section of the NAcc was processed using a floating immunohistochemistry procedure. Sections were washed with $\mathrm{PB}$ saline (PBS; $0.01 \mathrm{~m}$ ), $\mathrm{pH} 7.4$, at room temperature three times for $5 \mathrm{~min}$ between all steps. Sections were incubated for $30 \mathrm{~min}$ in $1 \%$ bovine serum albumin (BSA; Sigma-Aldrich) to block nonspecific binding, and then incubated overnight $(\sim 18 \mathrm{~h})$ in rabbit polyclonal antibody directed against c-Fos (Calbiochem, catalog \#Ab-5, Research Resource Identifier: AB_2307659) in 1\% BSA/PBS containing $0.2 \%$ Triton $\mathrm{X}-100$. Sections were incubated for $30 \mathrm{~min}$ in biotinylated goat anti- 
rabbit IgG (Vector Laboratories) in $0.1 \mathrm{M}$ PBS and for $30 \mathrm{~min}$ in the avidin-biotin-horseradish peroxidase complex (Vectastain Elite Kit, Vector Laboratories). Staining was visualized using the chromogen substrate, VIP (Very Intense Purple; Vector Laboratories). Sections were then mounted on gelatinized slides, dehydrated, and coverslipped for light microscopy.

High-resolution images were acquired at $2 \times$ magnification using an Olympus VS-120 virtual slide system and the NAccSh was delineated using criteria from Paxinos and Watson (2007). c-Fos was quantified by a trained rater blinded to experimental condition. Bilateral counts were made of c-Fos-positive cells in NAccSh and NAccCo. In all animals, we quantified four sections containing both structures (ranging from +2.28 to $+1.00 \mathrm{~mm} \mathrm{AP}$ ). NAccSh and NAccCo counts were then averaged across sections to create the c-Fos score for each structure within a given animal.

Statistical analyses. In the yoked control experiment, daily average avoidance responses during the three sessions of SigAA training, expressed as a percentage of the total possible avoidance responses, were analyzed with a two-way ANOVA with a between-subjects factor of group (master and yoke) and a withinsubjects factor of session (days 1-3 of SigAA). Avoidance and c-Fos data from the US-free test session were analyzed using separate $t$ tests comparing master and yoke groups. In pharmacological studies (NAccSh, NAccCo, and BA-NAccSh inactivation experiments), daily average avoidance responses, also expressed as a percentage, were analyzed with separate twoway ANOVAs. Each of these had a betweensubjects factor of group (muscimol and vehicle for NAccSH and NAccCo experiments; contralateral muscimol, ipsilateral muscimol, and vehicle for BA-NAccSh experiment) and a within-subjects factor of session (days 3-5 of SigAA). We analyzed data from sessions $3-5$ of SigAA because they enabled us to compare inactivation to asymptotic levels of avoidance responding both before and after. ANOVAs were followed with $t$ tests performed on data from session 4 of SigAA (i.e., the day of muscimol infusion). In the aversive Pavlovian conditioning experiment, CS freezing at the LTM test, expressed as a percentage of the total possible conditioned response, was analyzed with a two-way ANOVA with a between-subjects factor of group (muscimol or vehicle in NAccSh) and a within-subjects factor of trial (five CS presentations). All data were analyzed and graphed using Graphpad Prism.

\section{Results}

\section{NAccSh c-Fos is activated in animals performing SigAA}

To determine whether SigAA behavior recruits NAcc, we trained subjects in a yoked control paradigm and then exposed all animals to 10 unreinforced avoidance CSs in an unyoked US-free test. Ninety minutes later, animals were killed and their brains processed for c-Fos immunoreactivity. Avoidance responses from the 3 days of SigAA training were analyzed using a two-way ANOVA with a between-subjects factor of group and a within-subjects factor of session. This analysis revealed a main effect for group $\left(F_{(2,21)}=133.06, p<0.0001\right)$, confirming that masters $(n=9)$ avoided more than yokes $(n=$ 9; Fig. 1A). We also compared avoidance responses from the US-free test, in which both masters and yokes could inactivate the CS by shuttling. A two-tailed $t$ test revealed that animals in the master group avoided more than yoked controls $(p<$ 0.01 ), demonstrating that masters, but not yokes, acquired the avoidance contingency (Fig. $1 B$ ).

We then examined NAccSh and NAccCo c-Fos levels in master $(n=9)$, yoke $(n=9)$, and box control $(n=6)$ groups. For NAccSh, mean \pm SEM c-Fos counts were as follows: master, $311.16 \pm 31.94$; yoke, $176.40 \pm 34.00$; box control, $116.32 \pm$ 34.12. One-way ANOVA revealed a significant effect for group $\left(F_{(2,20)}=10.35, p<0.001\right)$. Tukey's post hoc tests confirmed that this effect was driven by increased $c$-Fos in masters relative to yokes $(p<0.05)$ and in masters relative to box controls $(p<$ 0.0001 ), while there was no difference between yokes and box controls (Fig. 1B). Thus, masters both avoided more and had higher levels of NAccSh c-Fos immunoreactivity at test. Representative photomicrographs illustrate differing densities of c-Fos-positive cells in NAccSh across master, yoke, and box control groups (Fig. 1C-E).

For NAccCo, the mean \pm SEM c-Fos counts were as follows: master, $170.58 \pm 35.45$; yoke, $118.52 \pm 27.42$ ); box control, $76.41 \pm 24.63$. One-way ANOVA revealed no effect across these groups (data not shown). Thus, NAccCo c-Fos immunoreactivity did not differ significantly between masters and yokes. On the 
A

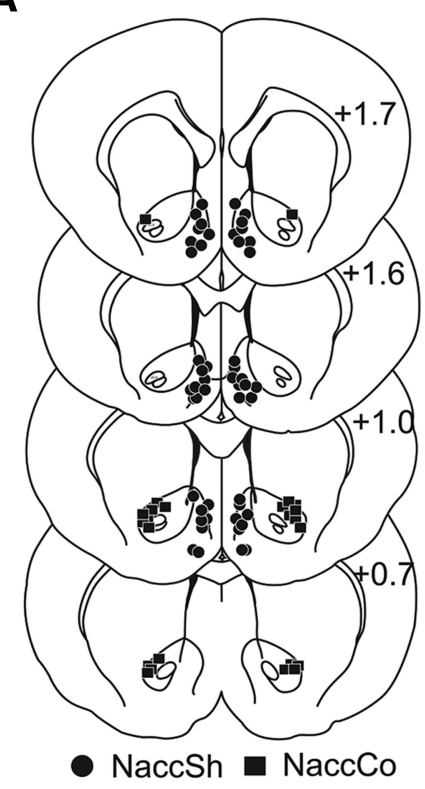

B

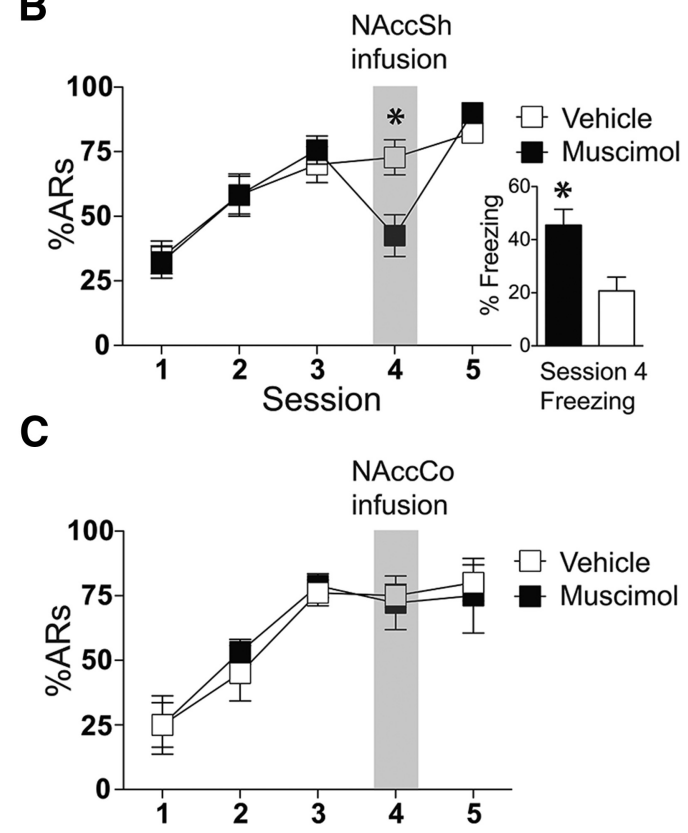

Figure 2. Effects of NAccSh and NAccCo inactivation on SigAA performance. $A$, Sites of NAccSh $(-)$ and $N A c c C o(\square)$ cannula hits for SigAA experiments. Images modified and AP values from Paxinos and Watson, second edition (1998). B, Muscimol infusions $(n=13)$ in NAccSh decreased avoidance responding (ARs, ${ }^{*} p<0.0001$ ) and increased freezing behavior (inset; ${ }^{*} p<0.01$ ) relative to vehicle infusions $(n=13)$. C, NAccCo muscimol infusion had no effect on SigAA performance. Bars represent \pm SEM.

basis of these data, we conclude that successful expression of SigAA behavior selectively recruits NAccSh, but not NAccCo.

\section{Inactivation of NAccSh, but not NAccCo, impairs SigAA expression and has no effect on the expression of Pavlovian conditioning}

To examine whether NAcc is necessary for the expression of SigAA behavior, animals were prepared with cannulae aimed at NAccSh or the adjacent NAccCo (Fig. 2A). In separate experiments, subjects were given three sessions of SigAA training before a fourth session in which we inactivated NAccSh or NAccCo. Subjects were then given an additional fifth session to re-establish baseline levels of avoidance behavior.

For the NAccSh experiment, subjects were divided into musci$\operatorname{mol}(n=13)$ or vehicle $(n=13)$ groups with $16 \%$ of animals $(n=5)$ excluded for poor performance during training. We analyzed avoidance behavior from the third through the fifth sessions of SigAA using a two-way ANOVA with a between-subjects factor of group and a within-subjects factor of session. This analysis revealed a group $\times$ session interaction $\left(F_{(2,48)}=9.364, p<0.001\right)$, which $t$ test confirmed was due to a significant decrease in avoidance responses made by the muscimol group on the day of infusion $(p<0.0001)$. Thus, NAccSh inactivation attenuated the expression of avoidance behavior (Fig. 2B).

Inactivation of NAccSh also caused a complementary increase in escape responses. For each group, the mean \pm SEM escape responses were as follows: muscimol, $15.93 \pm 2.343$ responses; vehicle, $7.714 \pm 1.894$ responses. Two-tailed $t$ test confirmed a significant increase in muscimol-treated animals $(p=0.0113)$. NAccSh inactivation prolonged the latency to escape. The mean \pm SEM escape latencies were as follows: muscimol, $1.77 \pm 0.243 \mathrm{~s}$; vehicle, $1.07 \pm 0.154 \mathrm{~s}$. Two-tailed $t$ test confirmed a significant difference between these groups $(p<$ 0.05). Thus, while NAccSh inactivation did not prevent ani- mals from escaping the US, it did slightly prolong the latency to do so.

As a control for any nonspecific motor effects of NAccSh inactivation, we quantified the rate of intertrial shuttling. For each group, the mean \pm SEM intertrial shuttling rates were as follows: muscimol, $1.541 \pm 0.2012 \mathrm{responses} / \mathrm{min}$; vehicle, 1.498 ( \pm 0.1919$)$ responses $/ \mathrm{min}$. Twotailed $t$ test showed no difference between muscimol and vehicle groups. We conclude that NAccSh inactivation strongly impaired the avoidance response and slowed the escape response, and that neither effect is attributable to a gross motor deficit.

To determine whether NAccSh muscimol had a parallel effect on Pavlovian defensive behaviors that occur in SigAA, we measured CS-evoked freezing during the fourth session. A two-tailed $t$ test revealed that inactivation of NAccSh increased freezing relative to vehicle controls $(p<$ 0.01 ), suggesting that inactivation of NAccSh has opposite effects on CSevoked actions and reactions in the SigAA paradigm (Fig. 2B).

For the NAccCo inactivation experiment, subjects were also divided into muscimol $(n=6)$ and vehicle $(n=6)$ groups with $14 \%$ of animals $(n=2)$ excluded for poor performance during training. We analyzed data from the third through the fifth sessions of SigAA with an ANOVA identical to that described above. This analysis revealed no effects, demonstrating that NAccCo is not required for the expression of avoidance behavior (Fig. 2C).

At test, escape responses were highly comparable between NAccCo muscimol (7.33 \pm 0.1815 responses) and vehicle (8.167 \pm 3.135 responses); two-tailed $t$ test revealed no difference between groups. Escape latencies were also very similar between NAccCo muscimol $(0.8687 \pm 0.4809 \mathrm{~s})$ and vehicle $(0.6907 \pm$ $0.1393 \mathrm{~s}$ ); again, two-tailed $t$ test revealed no difference between groups. Finally, the rates of intertrial shuttling were similar for NAccCo muscimol (1.017 \pm 0.128 responses/min $)$ and vehicle $(0.775 \pm 0.182$ responses $/ \mathrm{min})$; two-tailed $t$ test revealed no difference between groups. We conclude that NAccCo does not contribute to avoidance, escape, or intertrial shuttling in our SigAA paradigm.

Because NAccSh inactivation increased CS-evoked freezing during SigAA, we examined the effects of NAccSh muscimol on the expression of a purely Pavlovian memory. Animals were prepared with cannulae aimed at NAccSh (Fig. $3 A$ ) before receiving three CS-US pairings and a test for the expression of CS freezing. Before the test, subjects received either intracranial infusions of muscimol $(n=6)$ or vehicle $(n=7)$. CS-freezing data were analyzed using a two-way ANOVA with a between-subjects factor of drug and a within-subjects factor of trial. This analysis revealed no effects, suggesting that NAccSh inactivation had no effect on the expression of conditioned defensive reactions (Fig. 3B).

We also tested the effects of NAccSh inactivation on the SigAA CS presented in an undivided chamber that did not allow shuttling, enabling us isolate Pavlovian reactions from the avoidance response. Animals were prepared with cannulae aimed at NAccSh (Fig. 3C). After three sessions of SigAA, animals were 
infused with muscimol $(n=5)$ or vehicle $(n=5)$ and exposed to CSs in a chamber identical to that used for the LTM test in the previous experiment. Freezing data were analyzed using a two-way ANOVA with a between-subjects factor of drug and a within-subjects factor of trial. No significant differences were found (Fig. 3D). We conclude that NAccSh inactivation enhances freezing in the SigAA context, but has no effect on freezing in tests of strictly Pavlovian memory, suggesting that animals revert to CS-evoked reactions when the substrates of CS-evoked action are disrupted.

\section{Disconnection of NAccSh and BA during SigAA impairs avoidance responding}

To test the serial progression of information from BA to NAccSh, we prepared animals with cannulae aimed at both BA and NAccSh to reversibly disconnect these structures during the fourth session of SigAA (Fig. $4 A, C$ ), as above. Subjects were divided into three groups: contralateral inactivation (i.e., disconnection, $n=9$ ), ipsilateral inactivation $(n=5)$, and vehicle (consisting of both contralateral and ipsilateral subjects, $n=11$ ) with $14 \%$ of animals $(n=4)$ excluded for poor performance during training. Using a two-way ANOVA with a within-subjects factor of session and a between-subjects factor of group, we analyzed avoidance responses from the third through the fifth sessions of SigAA, as above. This analysis revealed a group $\times$ session interaction $\left(F_{(4,46)}=\right.$ $10.90, p<0.0001)$, which $t$ tests confirmed was driven by a significant decrease in avoidance responses performed by the contralateral inactivation group during the fourth session, relative to both ipsilateral inactivation $(p<0.0001)$ and vehicle $(p<0.0001)$ groups (Fig. $4 B)$. On the basis of these anatomical and pharmacological data, we conclude that the serial progression of information from BA to NAccSh is required for the expression of avoidance behavior.

At test, disconnection produced a profile of escape responses that complemented the avoidance data. For each group, the mean \pm SEM escape responses were as follows: contralateral muscimol, $21.44 \pm 1.65$ responses; ipsilateral muscimol, $5.8 \pm 1.93$ responses; vehicle, $4.778 \pm$ 1.281 responses. One-way ANOVA revealed a significant effect for group $\left(F_{(2,25)}=\right.$ 42.16, $p<0.0001$ ), which Tukey's post hoc tests confirmed was driven by differences between contralateral and ipsilateral groups $(p<0.001)$, as well as between

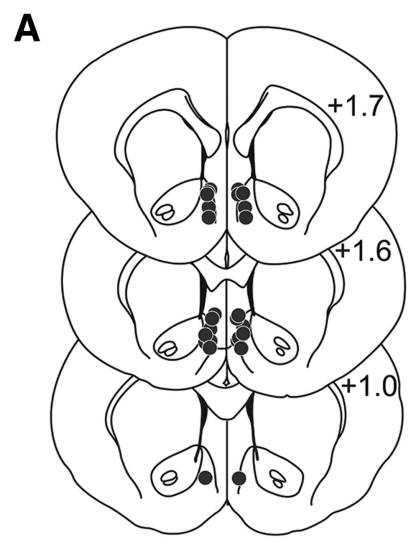

B

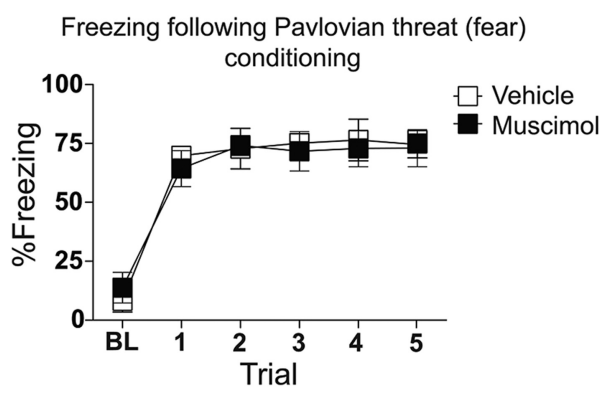

C

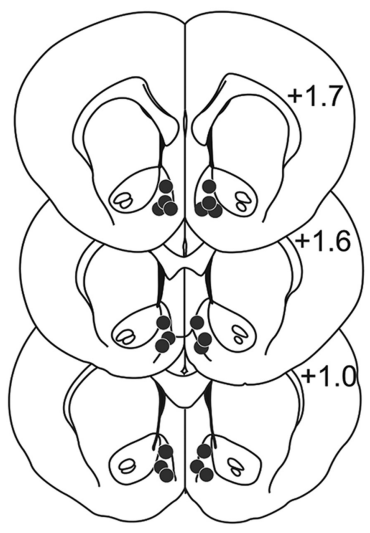

D

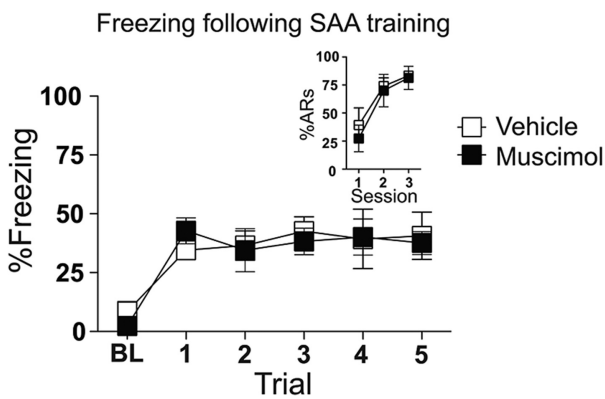

Figure 3. Effects of NAcCSh inactivation on CS-evoked freezing following aversive Pavlovian conditioning or SigAA training. $A$, Cannula hits for the aversive Pavlovian conditioning experiment. Numbers represent AP position from bregma (Paxinos and Watson, 1998). B, Following Pavlovian conditioning, muscimol $(n=6)$ infusion had no effect on CS-elicited freezing relative to vehicle $(n=7)$ infusions. $C$, Cannula hits for CS-test experiment. $\boldsymbol{D}$, When the SigAA CS was tested in a context that did not allow the avoidance response, muscimol ( $n=5)$ infusion had no effect on CS-elicited freezing relative to vehicle $(n=5)$ infusions. Images for cannula targeting modified from Paxinos and Watson, second edition (1998). Bars represent \pm SEM.
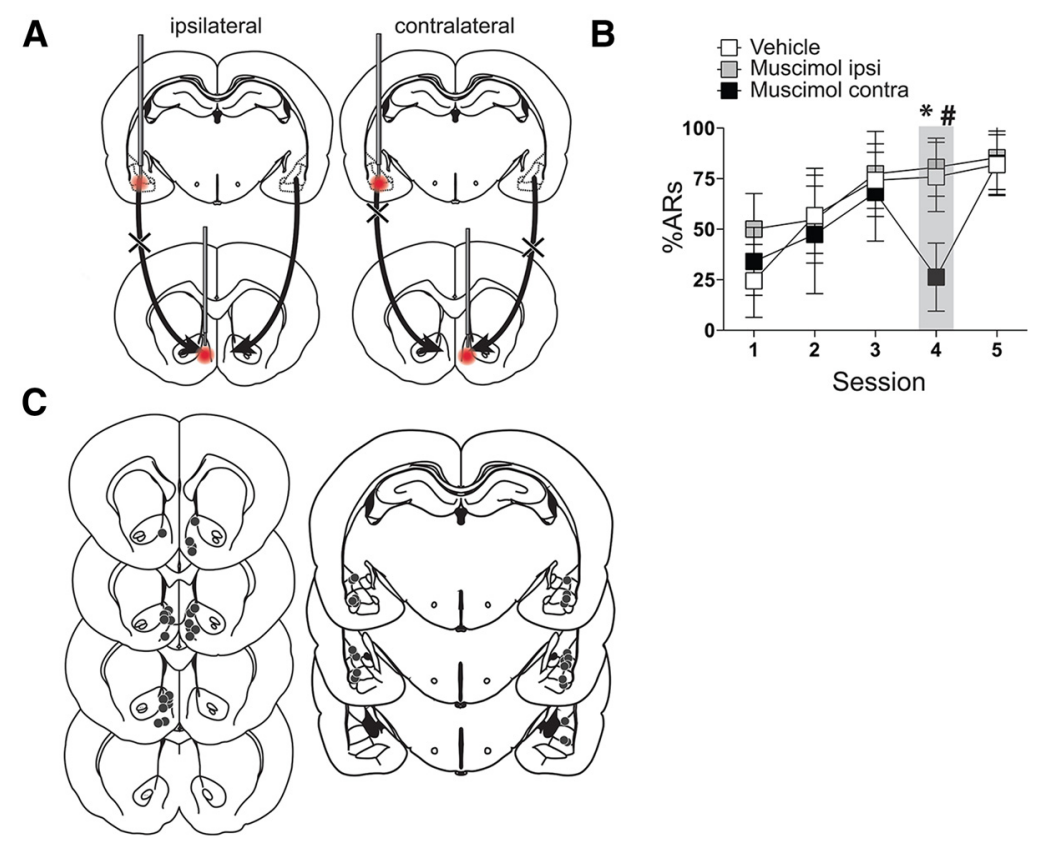

Figure 4. Effects of BA-NAcCSh disconnection on SigAA. A, Schematic showing the consequence of contralateral and ipsilateral inactivation of $B A$ and NAccSh on the serial progression of information across the circuit. $B$, Contralateral muscimol infusions $(n=$ 9) in BA and NAccSh impaired SigAA compared with ipsilateral muscimol infusions $(n=5, \# p=0.0001)$ and vehicle infusions $\left(n=11 ;{ }^{*} p=0.0001\right)$. C, Cannula hits for the BA-NAcCSh disconnection experiment. Images were modified from Paxinos and Watson, second edition (1998). Bars represent \pm SEM. 
A

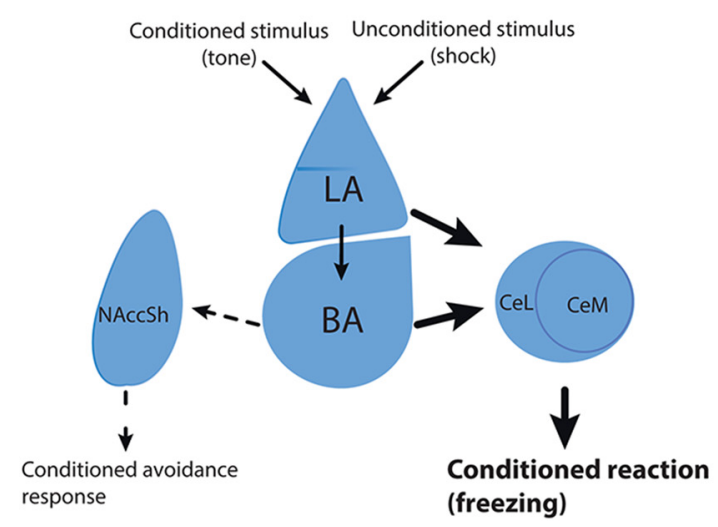

B

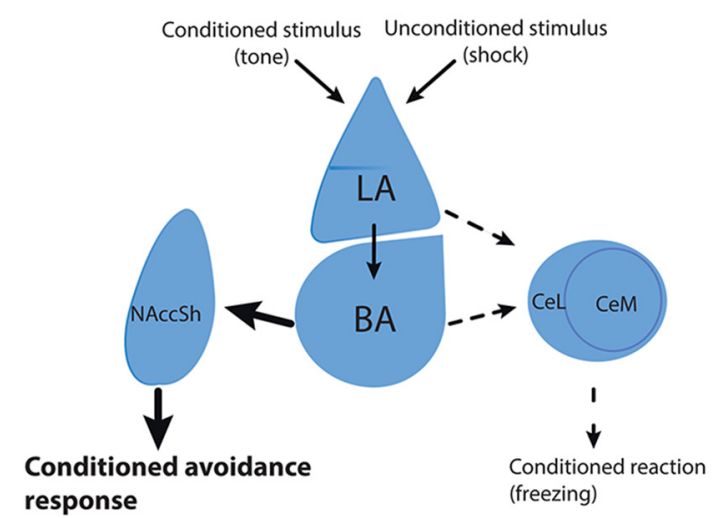

Figure 5. Pathways through the amygdala mediating different CS-evoked behaviors. $A$, The expression of CS-evoked reactions, such as freezing, depends LA, BA, and long-range projections arising from CeA. $B$, The expression of CS-evoked actions, such as avoidance, also depends on LA and BA. However, the necessary amygdalar outputs arise directly from BA. CS-evoked reactions are known to require CeA projection targets, such as periaqueductal gray, while CS-evoked actions require the BA projection to NAccSh.

contralateral and vehicle groups $(p<0.001)$, but there was no difference between ipsilateral and vehicle groups. Thus, disconnection impaired avoidance while causing a complementary increase in escapes. However, this was not associated with a significant increase in escape latency. For each group, the mean \pm SEM escape latencies were as follows: contralateral muscimol, $1.836 \pm 0.35 \mathrm{~s}$; ipsilateral muscimol, $0.65 \pm 0.13 \mathrm{~s}$; vehicle, $1.31 \pm$ 0.4408 s. One-way ANOVA revealed no significant difference between groups. Thus, while bilateral NAccSh inactivation had an effect on escape latency, this behavioral measure does not seem to depend on the flow of information from BA to NAccSh.

As a control for any nonspecific motor effects of disconnection, we quantified the rate of intertrial shuttling. For each group, the mean \pm SEM rate was as follows: contralateral muscimol, $0.99 \pm 0.24$ responses/min; ipsilateral muscimol, $1.66 \pm 0.33$ responses/min; vehicle, $1.32 \pm 0.17$ responses $/ \mathrm{min}$. One-way ANOVA revealed no difference between groups. We conclude that BA/NAccSh disconnection exerted a selective effect on avoidance, without any broad motor impairment.

\section{Discussion}

In this report, we demonstrate that defensive actions triggered by an aversive $\mathrm{CS}$ depend on a functional circuit including the BA and NAccSh. In an initial c-Fos experiment with a yoked control design, SigAA behavior increased c-Fos expression in the NAccSh of master subjects relative to yokes. In contrast, c-Fos expression in the NAccCo did not differ across groups. Correspondingly, inactivation of NAccSh with muscimol attenuated the output of avoidance behavior, while inactivation of NAccCo had no effect. Asymmetric inactivation of BA and NAccSh decreased the expression of active avoidance, suggesting that a functional connection between the two structures is vital for aversively motivated action. Because BA sends a direct, nonreciprocal projection to NAccSh, we conclude that BA conveys crucial information about the avoidance CS to NAcc, which is a known interface between motivational processing and motor control systems (Mogenson et al., 1980; Cain and LeDoux, 2008; Elliot, 2008).

The two-factor theory of SigAA holds that avoidance learning occurs in two distinct phases. The first phase is Pavlovian, in which the subject learns that the CS predicts the US, and the second phase is instrumental, in which the subject learns that a particular behavior causes CS termination (Mowrer and Lamoreaux, 1946; Miller, 1948; Cain and LeDoux, 2007). As SigAA is acquired, the subject transitions from a behavioral profile dominated by Pavlovian reactions (freezing) to CS-evoked actions (avoidance). Our results suggest that the flow of information from BA to NAccSh is most relevant to the latter phase of the two-factor process. While NAccSh inactivation increases CSevoked freezing during an avoidance session, the same treatment has no effect on freezing in a strictly Pavlovian paradigm, or on freezing evoked by the SigAA CS when tested in an environment that does not allow the avoidance response. This suggests that the animal reverts back to Pavlovian reactions when the substrate of avoidance is unavailable.

When considered in the context of the broader literature, our data suggest an intriguing model for how contrasting responses to the CS are processed in the amygdala and beyond (Fig. 4). The LA is an important site for the storage of CS-US associations (McKernan and Shinnick-Gallagher, 1997; Grace and Rosenkranz, 2002; Tsvetkov et al., 2002; Sah et al., 2003; Maren, 2005; Schafe et al., 2005; Johansen et al., 2011). CS-evoked firing in LA neurons increases and decreases with the acquisition and extinction of aversive associations (Quirk et al., 1995, 1997; Repa et al., 2001; Goosens et al., 2003), suggesting that neuronal activity in LA reflects the acquired valence of the CS. LA is required for the expression of both aversive reactions and actions (Muller et al., 1997; Poremba and Gabriel, 1999; Amorapanth et al., 2000), as both categories of behavior require the predictive information encoded by LA neurons.

BA also plays a role in aversively motivated reactions and actions. Post-training BA lesion, as well as inactivation of BA, attenuates the expression of CS-evoked freezing (AngladaFigueroa and Quirk, 2005; Amano et al., 2011). BA lesion also impairs active avoidance behavior (Choi et al., 2010; LázaroMuñoz et al., 2010). Both CeA and NAcc receive robust projections from BA (Pitkänen et al., 2000), suggesting that BA is the point of divergence between the substrates of CS-evoked actions and reactions (Fig. 5).

From BA, Pavlovian reactions are triggered when CS information is processed through CeA before being disseminated to the brainstem effector sites that produce freezing and other innate responses (LeDoux et al., 1988; Kim et al., 1993). In contrast, CS information that triggers defensive actions, such as avoidance, moves from BA to NAccSh, possibly via the monosynpatic connection between the two structures. These distinct amygdalar 
outputs produce mutually exclusive profiles of defensive behavior, and CeA constrains the acquisition of SigAA (Moscarello and LeDoux, 2013). In animals that fail to acquire the avoidance response, conditioned freezing remains high and avoidance behavior can be rescued by CeA lesions (Choi et al., 2010; LázaroMuñoz et al., 2010). The subject's ability to transition from reactive to active CS-evoked responses suggests a mechanism that toggles between contrasting types of defensive behavior. A previous report from our laboratory demonstrates a role for infralimbic prefrontal cortex (ilPFC; Moscarello and LeDoux, 2013), which can exert feedforward inhibition on CeA and negatively regulate the expression of innate defensive behaviors, such as freezing (Sotres-Bayon and Quirk, 2010). Future research will examine how the amygdalar substrates of SigAA recruit ilPFC to facilitate defensive action.

NAcc has been characterized as an interface between motivational circuits and the extrapyramidal motor system, allowing biologically salient cues to guide adaptive behavior (Mogenson et al., 1980). Evidence from the appetitive literature suggests that NAcc performs an important gating function (Pennartz et al., 1994; Taha and Fields, 2006; Ambroggi et al., 2008). In dissociable cell populations that are innately tuned to encode valence, NAcc firing can be evoked by either appetitive or aversive CSs (Roitman et al., 2005). Thus, NAcc guides behavior by filtering out irrelevant stimuli so that motivationally salient information can be used to organize action.

NAccSh sends a robust projection to the medial ventral pallidum, which in turn projects to the medial dorsal thalamus (Groenewegen et al., 1999; Sesack and Grace, 2010). The ilPFC receives thalamic input from the mediodorsal thalamus and sends projections back to NAccSh (Berendse et al., 1992; O'Donnell et al., 1997). Thus, NAccSh and ilPFC are part of a broad corticostriatal loop of synaptic connections (Graybiel, 2000). Such a large-scale network could facilitate various aspects of SigAA behavior. Information about the avoidance contingency could be gated through NAccSh and passed across a disynaptic connection to ilPFC, engaging that structure to suppress the Pavlovian reactions that obstruct SigAA (Moscarello and LeDoux, 2013). The projection from ilPFC to NAccSh creates a recurrent circuit, across which reverberating patterns of activity could sustain avoidance behavior over time. This arrangement would allow information originating from a small subset of BA neurons to organize the activity of large ensembles across the forebrain. NAccCo, on the other hand, participates in a parallel corticostriatal circuit, involving the prelimbic PFC (O'Donnell et al., 1997; Groenewegen et al., 1999; Sesack and Grace, 2010). Neither inactivation of NAccCo nor lesion of prelimbic PFC (Moscarello and LeDoux, 2013) has an effect on avoidance behavior, indicating that this system does not process information relevant to the two-way SigAA paradigm used in our laboratory. This is consistent with studies that demonstrate a role for NAccSh, but not NAccCo, in conditioned and unconditioned forms of aversion (Reynolds and Berridge, 2002, 2003).

To summarize, our data demonstrate that the flow of information from BA to NAcc is necessary for the expression of SigAA behavior. These results confirm that dissociable amygdalar outputs govern aversive actions and reactions, as we have previously hypothesized (Cain and LeDoux, 2008). While innate reactions, such as freezing, are the subject's first line of defense against expected threat, this BA-NAcc pathway is brought on-line when learned contingencies enable the subject to actively manipulate the environment to produce the most adaptive result.

\section{References}

Amano T, Duvarci S, Popa D, Paré D (2011) The fear circuit revisited: contributions of the basal amygdala nuclei to conditioned fear. J Neurosci 31:15481-15489. CrossRef Medline

Ambroggi F, Ishikawa A, Fields HL, Nicola SM (2008) Basolateral amygdala neurons facilitate reward-seeking behavior by exciting nucleus accumbens neurons. Neuron 59:648-661. CrossRef Medline

Amorapanth P, Nader K, LeDoux JE (1999) Lesions of periaqueductal gray dissociate-conditioned freezing from conditioned suppression behavior in rats. Learn Mem 6:491-499. CrossRef Medline

Amorapanth P, LeDoux JE, Nader K (2000) Different lateral amygdala outputs mediate reactions and actions elicited by a fear-arousing stimulus. Nat Neurosci 3:74-79. CrossRef Medline

Anglada-Figueroa D, Quirk GJ (2005) Lesions of the basal amygdala block expression of conditioned fear but not extinction. J Neurosci 25:96809685. CrossRef Medline

Berendse HW, Galis-de Graaf Y, Groenewegen HJ (1992) Topographical organization and relationship with ventral striatal compartments of prefrontal corticostriatal projections in the rat. J Comp Neurol 316:314-347. CrossRef Medline

Cain CK, LeDoux JE (2007) Escape from fear: a detailed behavioral analysis of two atypical responses reinforced by CS termination. J Exp Psychol Anim Behav Process 33:451-463. CrossRef Medline

Cain CK, LeDoux JE (2008) Chapter 3.1: brain mechanisms of Pavlovian and instrumental aversive conditioning. In: Handbook of behavioural neuroscience (Blanchard RL, Blanchard DC, Griebel G, Nutt D, eds), vol. 17, pp. 103-124. Amsterdam: Elsevier. CrossRef

Cardinal RN, Parkinson JA, Hall J, Everitt BJ (2002) Emotion and motivation: the role of the amygdala, ventral striatum, and prefrontal cortex. Neurosci Biobehav Rev 26:321-352. CrossRef Medline

Choi JS, Cain CK, LeDoux JE (2010) The role of amygdala nuclei in the expression of auditory signaled two-way active avoidance in rats. Learn Mem 17:139-147. CrossRef Medline

Corbit LH, Balleine BW (2005) Double dissociation of basolateral and central amygdala lesions on the general and outcome-specific forms of Pavlovian-instrumental transfer. J Neurosci 25:962-970. CrossRef Medline

Corbit LH, Muir JL, Balleine BW (2001) The role of the nucleus accumbens in instrumental conditioning: evidence of a functional dissociation between accumbens core and shell. J Neurosci 21:3251-3260. Medline

Delgado MR, Nearing KI, Ledoux JE, Phelps EA (2008) Neural circuitry underlying the regulation of conditioned fear and its relation to extinction. Neuron 59:829-838. CrossRef Medline

Di Ciano P, Everitt BJ (2004) Direct interactions between the basolateral amygdala and nucleus accumbens core underlie cocaine-seeking behavior by rats. J Neurosci 24:7167-7173. CrossRef Medline

Elliot AJ (2008) Introduction and overview: approach and avoidance motivation. In: Handbook of approach and avoidance motivation (Elliot AJ, ed). London: Psychology.

Faneslow MS (1994) Neural organization of the defensive behavior system responsible for fear. Psychon Bull Rev 1:429-438. CrossRef Medline

Feather NT (1963) Mowrer's revised two-factor theory and the motiveexpectancy-value model. Psychol Rev 70:500-515. CrossRef Medline

Goosens KA, Hobin JA, Maren S (2003) Auditory-evoked spike firing in the lateral amygdala and Pavlovian fear conditioning: mnemonic code or fear bias? Neuron 40:1013-1022. CrossRef Medline

Grace AA, Rosenkranz JA (2002) Regulation of conditioned responses of basolateral amygdala neurons. Physiol Behav 77:489-493. CrossRef Medline

Graybiel AM (2000) The basal ganglia. Current biology: CB 10:R509-R511. CrossRef Medline

Groenewegen HJ, Wright CI, Beijer AV, Voorn P (1999) Convergence and segregation of ventral striatal inputs and outputs. Ann N Y Acad Sci 877: 49-63. CrossRef Medline

Haselgrove M, Esber GR, Pearce JM, Jones PM (2010) Two kinds of attention in Pavlovian conditioning: evidence for a hybrid model of learning. J Exp Psychol Anim Behav Process 36:456-470. CrossRef Medline

Johansen JP, Cain CK, Ostroff LE, LeDoux JE (2011) Molecular mechanisms of fear learning and memory. Cell 147:509-524. CrossRef Medline

Kelley AE, Domesick VB, Nauta WJ (1982) The amygdalostriatal projection in the rat - an anatomical study by anterograde and retrograde tracing methods. Neuroscience 7:615-630. CrossRef Medline

Kim JJ, Rison RA, Fanselow MS (1993) Effects of amygdala, hippocampus, 
and periaqueductal gray lesions on short- and long-term contextual fear. Behav Neurosci 107:1093-1098. CrossRef Medline

Lázaro-Muñoz G, LeDoux JE, Cain CK (2010) Sidman instrumental avoidance initially depends on lateral and basal amygdala and is constrained by central amygdala-mediated Pavlovian processes. Biol Psychiatry 67: 1120-1127. CrossRef Medline

LeDoux JE, Iwata J, Cicchetti P, Reis DJ (1988) Different projections of the central amygdaloid nucleus mediate autonomic and behavioral correlates of conditioned fear. J Neurosci 8:2517-2529. Medline

Levis D (1989) The case for a two-factor theory of avoidance: do nonfear interpretations really offer an alternative. In: Contemporary learning theories: Pavlovian conditioning and the status of traditional learning theory (Klein SB, Mowrer RR, ed), pp 227-277. Hillsdale, NJ: Lawrence Erlbaum Associates.

Maren S (2001) Neurobiology of Pavlovian fear conditioning. Ann Rev Neurosci 24:897-931. CrossRef Medline

Maren S (2005) Synaptic mechanisms of associative memory in the amygdala. Neuron 47:783-786. CrossRef Medline

McAllister WR, McAllister DE, Douglass WK (1971) Inverse relationship between shock intensity and shuttle-box avoidance learning in rats: a reinforcement explanation. J Comp Physiol Psychol 74:426-433. CrossRef

McKernan MG, Shinnick-Gallagher P (1997) Fear conditioning induces a lasting potentiation of synaptic currents in vitro. Nature 390:607-611. CrossRef Medline

Miller NE (1948) Studies of fear as an acquirable drive. 1. Fear as motivation and fear-reduction as reinforcement in the learning of new responses. J Exp Psychol 38:89-101. CrossRef Medline

Mogenson GJ, Jones DL, Yim CY (1980) From motivation to action: functional interface between the limbic system and the motor system. Prog Neurobiol 14:69-97. CrossRef Medline

Moscarello JM, LeDoux JE (2013) Active avoidance learning requires prefrontal suppression of amygdala-mediated defensive reactions. J Neurosci 33:3815-3823. CrossRef Medline

Mowrer OH, Lamoreaux RR (1946) Fear as an intervening variable in avoidance conditioning. J Comp Psychol 39:29-50. CrossRef Medline

Muller J, Corodimas KP, Fridel Z, LeDoux JE (1997) Functional inactivation of the lateral and basal nuclei of the amygdala by muscimol infusion prevents fear conditioning to an explicit conditioned stimulus and to contextual stimuli. Behav Neurosci 111:683-691. CrossRef Medline

O’Donnell P, Lavín A, Enquist LW, Grace AA, Card JP (1997) Interconnected parallel circuits between rat nucleus accumbens and thalamus revealed by retrograde transynaptic transport of pseudorabies virus. J Neurosci 17:2143-2167. Medline

Paxinos G, Watson C (1998) The rat brain in sterotaxic coordinates, Ed 2. San Diego: Academic.

Paxinos G, Watson C (2007) The rat brain in sterotaxic coordinates, Ed 3. Amsterdam: Elsevier.

Pennartz CM, Groenewegen HJ, Lopes da Silva FH (1994) The nucleus accumbens as a complex of functionally distinct neuronal ensembles: an integration of behavioural, electrophysiological and anatomical data. Prog Neurobiol 42:719-761. CrossRef Medline

Pitkänen A, Jolkkonen E, Kemppainen S (2000) Anatomic heterogeneity of the rat amygdaloid complex. Folia morphologica 59:1-23. Medline

Poremba A, Gabriel M (1999) Amygdala neurons mediate acquisition but not maintenance of instrumental avoidance behavior in rabbits. J Neurosci 19:9635-9641. Medline

Quirk GJ, Repa C, LeDoux JE (1995) Fear conditioning enhances shortlatency auditory responses of lateral amygdala neurons: parallel recordings in the freely behaving rat. Neuron 15:1029-1039. CrossRef Medline

Quirk GJ, Armony JL, LeDoux JE (1997) Fear conditioning enhances different temporal components of tone-evoked spike trains in auditory cortex and lateral amygdala. Neuron 19:613-624. CrossRef Medline

Repa JC, Muller J, Apergis J, Desrochers TM, Zhou Y, LeDoux JE (2001) Two different lateral amygdala cell populations contribute to the initiation and storage of memory. Nat Neurosci 4:724-731. CrossRef Medline

Reynolds SM, Berridge KC (2002) Positive and negative motivation in nucleus accumbens shell: bivalent rostrocaudal gradients for GABA-elicited eating, taste "liking"/“disliking" reactions, place preference/avoidance, and fear. J Neurosci 22:7308-7320. Medline

Reynolds SM, Berridge KC (2003) Glutamate motivational ensembles in nucleus accumbens: rostrocaudal shell gradients of fear and feeding. Eur J Neurosci 17:2187-2200. CrossRef Medline

Roitman MF, Wheeler RA, Carelli RM (2005) Nucleus accumbens neurons are innately tuned for rewarding and aversive taste stimuli, encode their predictors, and are linked to motor output. Neuron 45:587-597. CrossRef Medline

Sah P, Faber ES, Lopez De Armentia M, Power J (2003) The amygdaloid complex: anatomy and physiology. Physiol Rev 83:803-834. Medline

Schafe GE, LeDoux JE (2000) Memory consolidation of auditory Pavlovian fear conditioning requires protein synthesis and protein kinase $\mathrm{A}$ in the amygdala. J Neurosci 20:RC96. Medline

Schafe GE, Doyère V, LeDoux JE (2005) Tracking the fear engram: the lateral amygdala is an essential locus of fear memory storage. J Neurosci 25:10010-10014. CrossRef Medline

Schoenbaum G, Setlow B (2003) Lesions of nucleus accumbens disrupt learning about aversive outcomes. J Neurosci 23:9833-9841. Medline

Sears RM, Fink AE, Wigestrand MB, Farb CR, de Lecea L, Ledoux JE (2013) Orexin/hypocretin system modulates amygdala-dependent threat learning through the locus coeruleus. Proc Natl Acad Sci U S A 110:2026020265. CrossRef Medline

Sesack SR, Grace AA (2010) Cortico-basal ganglia reward network: microcircuitry. Neuropsychopharmacology 35:27-47. CrossRef Medline

Shiflett MW, Brown RA, Balleine BW (2010) Acquisition and performance of goal-directed instrumental actions depends on ERK signaling in distinct regions of dorsal striatum in rats. J Neurosci 30:2951-2959. CrossRef Medline

Sotres-Bayon F, Quirk GJ (2010) Prefrontal control of fear: more than just extinction. Curr Opin Neurobiol 20:231-235. CrossRef Medline

Stuber GD, Britt JP, Bonci A (2012) Optogenetic modulation of neural circuits that underlie reward seeking. Biol Psychiatry 71:1061-1067. CrossRef Medline

Taha SA, Fields HL (2006) Inhibitions of nucleus accumbens neurons encode a gating signal for reward-directed behavior. J Neurosci 26:217-222. CrossRef Medline

Tsvetkov E, Carlezon WA, Benes FM, Kandel ER, Bolshakov VY (2002) Fear conditioning occludes LTP-induced presynaptic enhancement of synaptic transmission in the cortical pathway to the lateral amygdala. Neuron 34:289-300. CrossRef Medline 